\title{
ENSAIO DE SÍNTESE: CONCEITO DE IMAGINAÇÃO NA CRÍTICA LITERÁRIA DO ROMANTISMO BRASILEIRO
}

\author{
Jéssica Cristina Jardim
}

RESUMO: No campo da teoria e da crítica literária, como conceito-chave do romantismo, o termo imaginação é ressignificado, ora como gênese da obra artística, ora como um de seus atributos. Compreendendo a literatura brasileira, e seus conceitos adjuntos, como "síntese de tendências universalistas e particularistas", buscamos as bases que servem à formulação do conceito estudado e suas definições em dicionários, prefácios e críticas. Referida textualmente como controversa faculdade ou potência de imitação e memória, por vezes patológica e submissa a outras instâncias, como a razão, a história e a linha narrativa, a imaginação é ainda percebida como essência da criação literária.

PALAVRAS-CHAVE: Imaginação; Romantismo brasileiro; Teoria e crítica literárias no século XIX.

ABSTRACT: In the fields of literary theory and criticism, and as a key concept of Romanticism, imagination is resignified as the genesis of artistic work, as well as one of its attributes. Understanding Brazilian literature and its adjunctive concepts as "a synthesis of universalist and particularist tendencies", we seek the sources which serve to form the studied concept and its definitions in dictionaries, forewords and critiques. Referred to as a controversial faculty or the power of imitation and memory, sometimes pathological and submissive to other elements, such as reason, history, or narrative line, imagination is still perceived as the essence of literary creation.

KEYWORDS: Imagination; Brazilian Romanticism; Literary theory and criticism in the nineteenth century. 


\section{IMAGINAÇÃO: PERCEPÇÕES GERAIS SOBRE CRÍTICA E LITERATURA NO BRASIL}

Na acertada reflexão de João Alexandre Barbosa, no momento em que Machado de Assis lança um olhar sobre o quadro geral das manifestações literárias no Brasil produzidas até seu tempo, no fundamental ensaio "Instinto de nacionalidade", ele também havia apontado uma questão básica ao campo literário: "como passar, pela literatura, da história ao texto e como, pela crítica, refazer o caminho do texto à história, sem perder a tensão que os articula?". ${ }^{2}$ Em meio a definições fluidas de nacional e universal, e reconhecendo a legitimidade de uma nação recentemente independente buscar em sua história e em sua geografia os assuntos de sua literatura, Machado de Assis se contrapunha às doutrinas que impunham limites à criação literária, tornando-a, apenas, expressão de disciplinas que lhe seriam extrínsecas.

O olhar agudo de Machado de Assis é o de um escritor que, em 1873, havia podido perceber, com a devida distância crítica, as mudanças que fizeram parte do florescimento e da decadência do romantismo e do advento do realismo. Mas é principalmente o de um crítico que pôde observar de perto as reincidências temáticas e formais desse processo, centradas, sobretudo, no espelhamento da realidade nacional. Daí que o "sentimento íntimo", que tornaria um escritor representante legítimo "de seu tempo e do seu país, ainda quando trate de assuntos remotos no tempo e no espaço", ${ }^{2}$ se opusesse às tendências puramente descritivas e representativas que marcam principalmente as obras canônicas do período que corresponde ao da formação da literatura brasileira como consciência política e artística de si mesma: uma "literatura empenhada" no exercício de sua função histórica, uma literatura que deveria ser "interessada", ${ }^{3}$ no sentido que lhe deram Ferdinand Denis ${ }^{4}$ ou Almeida Garrett, ${ }^{5}$ legitimando a "brasilidade" como princípio e critério de valor para a escrita no país.

\footnotetext{
1 BArbosa, João Alexandre. A leitura do intervalo. São Paulo: Iluminuras, 1990, p. 43.

2 Assis, Machado de. "Instinto de nacionalidade". In: Assis, Machado de. Crítica literária: obras completas. Rio de Janeiro; São Paulo; Porto Alegre: W. M. Jackson, 1955, pp. 129-35.

3 CANDido, Antonio. Formação da literatura brasileira: momentos decisivos. Vol. 1: 1750-1836. 6 ed. Belo Horizonte: Itatiaia, 1981, pp. 27 e 28.

4 DENIs, Ferdinand. Scènes de la nature sous les Tropiques et de leur influence sur la poésie, suivies de Camoens et Jozé Índio. Paris: Louis Janet Libraire, 1824, p. 2.

5 GARrett, Almeida. "A restauração das letras, em Portugal e no Brasil, em meados do século xviıI". In: CÉSAR, Guilhermino (org.). Historiadores e críticos do romantismo. 1: A contribuição europeia: crítica e história literária. Rio de Janeiro: Livros Técnicos e Brasileiros; São Paulo: Edusp, 1978, pp. 87-92.
}

166. JARDIM, Jéssica Cristina. Ensaio de síntese: conceito de imaginação na crítica literária 
Embora, em uma análise posterior das obras canônicas do movimento romântico no Brasil, possamos dizer que em geral a imaginação foi negligenciada em prol de sentimentos nacionalistas e da descrição da realidade imediata - convertendo-se em "certa renúncia à imaginação ou certa incapacidade de aplicá-la devidamente à representação do real, resolvendo-se por vezes na coexistência de realismo e fantasia, documento e devaneio, na obra de um mesmo autor"6 -, não podemos afirmar com a mesma força que nossos escritores acreditassem a estar abandonando deliberadamente em prol de algo maior, nem em termos de ideias, nem em termos de obras literárias.

No campo das ideias, que nos interessa particularmente neste ensaio, essa "renúncia" à imaginação como modalidade da criação literária não se deu na mesma medida, nem de maneira tão deliberada. Em termos de resultado e construção de obras literárias, a ultrapassagem da representação da realidade empírica ocorreu livremente em obras de Bernardo Guimarães, Álvares de Azevedo, Agrário de Menezes, na poesia, no drama e nas narrativas imaginativas e lendárias brasileiras. No entanto, nas formulações teóricas e nas críticas, assim como em dicionários, o significado do termo imaginação se manteve em geral em equilíbrio quanto a um modo de representação entre o ideário setecentista e oitocentista.

Pensamos nos possíveis sentidos esparsos da imaginação ${ }^{7}$ na história das ideias e da literatura, e que retornam como síntese na literatura brasileira. No curso do desenvolvimento da teoria e da crítica literária, até o momento em que se torna um dos conceitos-chave do movimento romântico, o termo imaginação passa por diversas reformulações, que ora o situam na gênese da obra artística, ora o classificam como um de seus atributos. Desde a filosofia setecentista, até a passagem para a estética oitocentista, a imaginação é compreendida como a faculdade responsável pela concepção artística, além de ser um dos fundamentos do conhecimento humano, ao lado da razão e da memória, encontrando ainda outros sentidos particulares, que dizem respeito aos níveis de superação da realidade empírica convencionados e às possibilidades de exercício da subjetividade poética e do íntimo.

\footnotetext{
6 CANDIDO, Antonio, op. cit., pp. 27 e 28.

7 De início, é preciso dizer, diferenciamos a imaginação do conceito antropológico de "imaginário", compreendendo-a como a "fonte" deste e como uma modalidade presente nas poéticas literárias a partir do renascimento (LIMA, Luiz Costa. O controle do imaginário \& A afirmação do romance. São Paulo: Companhia das Letras, 2009, p. 110).
} 
Compreender os sentidos existentes textualmente para o termo imaginação no período do romantismo brasileiro envolve a tentativa mesma de atualizar esse conceito, homogeneizando o que aparece de maneira difusa na crítica e nas poéticas dos românticos brasileiros. Tomamos de empréstimo a definição de Antonio Candido, ${ }^{8}$ relativa à formação da literatura brasileira como "síntese de tendências universalistas e particularistas", devido aos contributos que ambas as estéticas setecentista e oitocentista forneceram para a gênese de nosso sistema literário, e compreendendo também como sintéticos os conceitos que dela fazem parte, como a imaginação e seus processos criativos.

\section{TESE E ANTÍTESE}

Na tentativa de elaborar um conceito sintético da imaginação na linguagem e na crítica literária brasileira romântica, chamamos de "tese" aos sentidos recebidos do século XVIII, e de "antítese" àqueles relacionados ao ideário oitocentista. Para a literatura brasileira, vem, sobretudo, da primeira o impulso de uma sistematização do campo literário, a partir de uma consciência estética fundada no rigor da forma e na contenção emocional, que constroem uma literatura de dimensões universalistas, centrados em seu caráter documental e descritivo; da segunda vem o nacionalismo herdado dos românticos, $o$ qual, embora justifique uma literatura que precisa assentar suas bases ideológicas, em geral, faz nossos escritores se voltarem ao caráter representativo da obra de arte, central na apreensão dos temas de conteúdo "brasileiro" - da cor local. Ambas têm consequências necessárias sobre os fundamentos do processo criativo da imaginação nas poéticas e críticas nacionais.

A tese da imaginação setecentista é mediada por certa concepção de mundo, cuja essência filosófica gira em torno do questionamento da legitimidade do conhecimento diante de uma realidade de aparências em mutação e que leva à colocação da razão, da memória e da sensação como centro desse sistema de pensamento, ${ }^{9}$ e que tem por

8 CANDIDO, Antonio, op. cit., pp. 27 e 28.

9 DOBRÁnszKy, Enid Abreu. No tear de Palas: imaginação e gênio no século XVIII: Uma introdução. Campinas: Papirus; Editora da Unicamp, 1992, p. 19. 
base, sobretudo, o pensamento sensualista, de Étienne de Condillac, ${ }^{10}$ e enciclopedista, de Diderot e D'Alembert. ${ }^{11}$ Embora essas filosofias se aproximem epistemologicamente, há uma linha tênue que as separa, que se situa justamente na relação que cada uma estabelece entre sensação, memória e imaginação.

Condillac afirma a primazia dos sentidos, tanto na construção do conhecimento, como na formação mesma das estruturas mais primárias da consciência humana, que termina excluindo necessariamente qualquer outra origem para o pensamento que não seja empírica; os enciclopedistas, apesar de seu materialismo, mencionam de passagem o papel das sensações para a formação do conhecimento humano. Apesar de os enciclopedistas destacarem que a memória se encontra na gênese da imaginação, eles não a confundem como categorias práticas na construção do conhecimento; o autor do Tratado das sensações, porém, chega mesmo a afirmar a identidade entre as duas faculdades, a imaginação sendo uma memória expandida, um mero atributo desta.

Não há exatamente uma ruptura entre essa tese e os posteriores desenvolvimentos da antítese que representa a imaginação no romantismo. Afinal, o século xIX não nega a construção racional e tampouco as sensações como fundamentais para a formação do conhecimento humano e da imaginação. Sua concepção se expande quando excede o terreno da realidade, base da percepção sensível, e escapa para o do possível, pela crítica à autossuficiência dos órgãos dos sentidos na construção do conhecimento. O modelo a ser seguido, salvo raras exceções, baseia-se na realidade empírica, e seu modo de apreensão para a arte está fundamentado, especialmente, no exercício dos sentidos, que possibilitam a própria existência da imaginação, compreendida essencialmente como a faculdade dos seres sensíveis responsável por imitar, representar, compor e presentificar ideias e objetos. De modo geral, a influência que chega ao Brasil por meio de dicionários das filosofias desse século é principalmente a da imaginação como uma modalidade da memória uma memória intensificada, sem dúvida, mas incapaz de altos graus de ficcionalização, limitando-se às impressões geradas pelos sentidos, restringindo-se à sua reprodução e ao seu reordenamento, e guardando alguns riscos patológicos ocasionados pelo seu excesso.

10 condillac, Étienne. Traité des sensations, augmenté de l'Extrait raisonné. Paris: Librairie Arthème Fayard, 1984 [1754], pp. 28 e 123.

11 Diderot, Denis; D’Alembert, Jean le Rond (dir.). Verbete “Imagination”. L’Encyclopédie ou Dictionnaire raisonné des sciences, des arts et des métiers (1751-1772). Tomo 6º Paris: Briasson; David l'Aîné; Le Breton; Durand, 1751, pp. 560-4. 
$\mathrm{Na}$ fronteira entre os séculos XVIII e XIX ocorre uma nova alteração da "face do mundo", que em muito contribui com a dilatação da categoria imaginação, assentada principalmente na emergência do desenvolvimento científico em fins do século XVIII e na retomada dos temas místicos e cristãos da Idade Média. ${ }^{12}$ Aparentemente contraditórias e excludentes, essas duas tendências têm em comum as novas possibilidades que abrem aos poetas românticos em sua busca por horizontes ainda desconhecidos. Ao se ligarem a diferentes graus de autonomização e intensidade como meios de se atingir uma percepção profunda do real, a imaginação e a literatura românticas alterariam todos os seus critérios de factualidade, no abandono voluntário da natureza empírica e na adoção de novas regras para a leitura de obras ficcionais, o que, no fim das contas, mudaria intrinsecamente a forma final das obras: não mais um critério de verdade, mas de suspensão da descrença diante de um mundo transfigurado, estranho e inabitual. Por outro lado, a afirmação do suprassensorial não se faria sem a consciência e a definição do sensorial - a compreensão da imaginação como espelho de reflexos fantásticos comunga igualmente com um ideal neoclássico de arte como reprodução de imagens do mundo circundante, embora no romantismo tal mundo seja significativamente ampliado.

Seja como uma faculdade desmedida e suprassensorial, seja como mediadora entre o espírito e a matéria, em vão se poderia buscar por uma definição unificada da imaginação como antítes $\mathrm{e}^{13} \mathrm{em}$ um movimento tão amplo e que prezava, ao contrário, pela não

\footnotetext{
12 SAliba, Elias Thomé. As utopias românticas. 2 ed. São Paulo: Estação Liberdade, 2003, p. 34.

13 Para a elaboração da antítese (conceito de imaginação oitocentista), acessamos aos seguintes documentos, dentre outros:

Chateaubriand, François René. “O gênio do cristianismo”. In: LOBo, Luiza (org.). Teorias poéticas do romantismo. Porto Alegre: Mercado Aberto, 1987, pp. 113-22;

COLERIDGE, Samuel Taylor. “Biographia Literaria”. In: LOBo, Luiza (org.), op. cit., pp. 188-207;

Cousin, Victor. Du vrai, du beau et du bien. 2 ed. augmentée d'un appendice sur l'art Français. Paris: Didier, 1854, p. 133;

HAZLITT, William. “Sobre a poesia em geral”. In: Lово, Luiza (org.), op. cit., pp. 208-13;

Hugo, Victor. La préface de Cromwell: introduction, texte et notes. Org. e Apres. de Maurice Souriau. Paris: Société Française d'Imprimerie et de Librairie, 1897, p. 199;

Lamartine, Alphonse de. "Primeiras meditações poéticas”. In: LOBO, Luiza (org.), op. cit., pp. 123-4; LАMв, Charles. “Sobre a comédia artificial do século passado”. In: LOBO, Luiza (org.), op. cit., pp. 245-9; NOVALIS. “Fragmentos logológicos (excertos)”. In: LOBO, Luiza (org.), op. cit., pp. 73-90; SCHILLER, Friedrich von. "Sobre o patético". In: LOBO, Luiza (org.), op. cit., pp. 35-41; SCHLEGEL, Friedrich. "Fragmentos da Athenaum (Excertos). In: LOво, Luiza (org.), op. cit., pp. 50-72;
} 
fixidez, pela renovação constante de seus próprios conceitos e poéticas, que defendia a busca por novas formas de expressão. Entretanto, é possível delineá-lo, a partir de seu maior grau de base sobre a realidade ou sobre a possibilidade. A pura imaginação escapa dos limites da mente para tornar-se mais objetiva, ou melhor, para reinventar o conceito de objetivo, de realidade concreta. As ideias que fazem parte tão somente da imaginação são também coisas, objetos, personagens, que passam a ter uma existência, abstrata, mas igualmente válida. Ao excesso de imaginação, ou à imaginação poética, cabe não apenas elaborar uma limitada representação do mundo, mas acrescentar a esta algo de grotesco e de fantástico, não se restringindo apenas ao sentido, ou seja, ao aspecto da obra de arte que poderia ser submetido unilateralmente à razão. $O$ papel da imaginação como um princípio gerativo inerente à natureza e dotado de um poder mágico e sintético possibilitaria a coexistência, na poesia, de ideias díspares, desde que harmonizadas. ${ }^{14}$

A imaginação não é tão somente uma faculdade de representação, que traz à tona resquícios de uma realidade já vivida, mas é um dos pilares essenciais da poesia, que se estende para além da mera ficcionalização de dados que partem do real. Essa autonomização em relação à memória representa a não obrigatoriedade de a imaginação seguir os preceitos de reprodução e reordenamento das impressões da realidade empírica recolhidas pelos sentidos. Assim, sua emancipação se dá por sua plena liberdade em representar mesmo as ideias que não se justificassem por uma razão exterior a elas mesmas - sua verossimilhança interna.

\section{ENSAIO DE SÍNTESE}

3.1 Etimologia do termo imaginação em dicionários de língua portuguesa nos séculos XVIII e XIX

Reafirmando o pano de fundo que dá lugar à posterior querela entre românticos e classicistas, e que tem como um dos fundamentos a imaginação e sua relação com a fantasia, com a razão e com a representação da realidade empírica, no Dicionário da língua portuguesa, de 1789, a imaginação é compreendida como uma "potência, com que a alma

ShElley, Percey Bisshe. “Defesa da poesia”. In: Lobo, Luiza (org.). op. cit., pp. 220-44; WORDSWORTH, William. "Prefácio às baladas líricas". In: LOBO, Luiza (org.), op. cit., pp. 169-87. 14 ABrams, M. H. O espelho e a lâmpada: teoria romântica e tradição crítica. Tradução de Alzira Vieira Allegro. São Paulo: Editora Unesp, 2010, p. 165. 
representa na fantasia algum objeto: imaginação viva, essa potência de conceber, ou perceber, e representar os objetos bem, e vivamente", ${ }^{15}$ segundo o ideal enciclopédico da imaginação como espelho do mundo circundante. A imaginação não é uma representação sem qualquer atributo: é preciso que o resultado da ação de imaginar seja dotado de "vivacidade". Mas seu sentido é proeminentemente realista, objetivo ou descritivo.

Já no Dicionário da língua brasileira, ${ }^{16}$ escrito em 1832, momento em que se estabelece o movimento romantismo no Brasil, a imaginação é tida por uma "faculdade da alma, com que [a alma] representa na fantasia alguma coisa" e, ainda, "a coisa imaginada", ideia que encontra ecos em Rousseau e principalmente em Chateaubriand, para o qual a alma, vinculada a Deus, fonte inesgotável da natureza, é seu sustentáculo. É significativo o fato de nesse dicionário a imaginação ser indicada como uma faculdade, e não como uma potência - chamam-se de "faculdades" as "disposições que a natureza dá às diversas espécies", enquanto a "potência" é a "força necessária para executar uma ação". Uma faculdade pode tornar-se inativa, se a potência lhe for removida. ${ }^{17} \mathrm{~A}$ imaginação, passando a ser considerada uma faculdade, torna-se, assim, uma das disposições naturais do ser humano, e não mais tão somente um impulso para determinada ação, o termo ganhando em autonomia. A imaginação produz "coisas" - segundo o mesmo dicionário da língua portuguesa, "nome geral de tudo o que há, ou pode haver e nós concebemos", assim, a existência empírica vem pressuposta na imitação.

No Grande dicionário português ou Tesouro da língua portuguesa, ${ }^{18}$ publicado em 1848, quando as tendências românticas são assimiladas e finalmente se decantam, a imaginação é vista como uma disposição inata ao ser humano, a

[...] faculdade de podermos conceber ideias acompanhadas d'impressões vivas dos fatos ou dos objetos, como se eles estivessem presentes. Essas ideias são particularmente o resultado da atividade própria das faculdades de concepção sintética e comparativa ou de generalização, atividade naturalmente em relação com o desenvolvimento dos órgãos correspondentes.

15 MORAIS SILva, Antonio de. Dicionário da língua portuguesa composto pelo padre Rafael Bluteau, reformado e acrescentado por Antonio de Morais Silva. Tomo 1 (A-K). Lisboa: Tipografia de Simões Tadeu Ferreira, 1789, p. 694.

16 silva pinto, Luiz Maria da. Dicionário da língua brasileira. Ouro Preto: Tipografia de Silva, 1832, s.p. 17 Roquete, J. I. Dicionário de sinônimos. Paris: Bijou, 1848, p. 280.

18 vieira, Frei Domingos. Grande dicionário português ou Tesouro da língua portuguesa. Porto: Ernesto Chardron e Bartholomeu H. de Moraes, 1873, s.p. 
A imaginação, pelo trabalho dos órgãos dos sentidos, se dá pela capacidade de representar objetos e ideias de forma tão intensa a ponto de torná-los presentes, concepção ambígua, já que, por um lado, comunga com o ideal setecentista de presentificação das impressões passadas; por outro lado, românticos como Hazlitt defenderiam a intensificação das impressões como importante elemento da imaginação. Uma conotação negativa, contudo, ainda permanece, ligando a imaginação à "crença”, à "opinião adquirida por imaginação" ou ao "pensamento imaginário", além de apresentar riscos à mente, se ela se sobrepujar à razão.

Nos três dicionários, ocorre uma transição entre os sentidos de imaginação, que passa de "potência" a "faculdade", o que marca sua autonomização no processo de elaboração de representações, de um impulso mental a uma disposição criativa inata dos seres humanos, sempre ligada, em maior ou menor grau, às sensações produzidas pelos órgãos dos sentidos. Se, de partida, não aparece relacionada necessariamente ao campo da arte, isso muda de figura, até tornar-se a faculdade criativa da mente artística. Nos três dicionários, a imaginação, quando em excesso, representa riscos à saúde mental. Outro aspecto, embora aparentemente sutil, é a forte ligação que esses verbetes possuem com a filosofia sensualista do século XVIII, em contrapartida com as filosofias e teorias do romantismo. É sintomático observar que nos três dicionários a imaginação é vista como uma faculdade fundamentalmente imagética, objetiva e de traços realistas e, assim, a ruptura com os modos de representação da realidade empírica raramente é anunciada. Ela permanece como função de reprodução de imagens captadas da realidade empírica pelos órgãos dos sentidos, mesmo nos dicionários produzidos no seio da estética romântica.

\subsection{Usos do termo imaginação na linguagem literária e da crítica brasileira oitocentista}

Buscamos observar não a aplicabilidade e as variantes da imaginação em obras literárias do romantismo brasileiro, mas os modos de uso do termo imaginação e os significados que recebe textualmente, ligados igualmente aos verbetes nos dicionários estudados e às influências filosóficas, críticas e literárias às quais recorremos e com as quais dialogam.

"A imaginação é um prisma brilhante, que reflete todas as cores, que decompõe os menores átomos de luz, que faz cintilar um raio do pensamento por cada uma de suas facetas diáfanas." ${ }^{19}$

19 Alencar, José de. Ao correr da pena. Org. José Maria Vaz Pinto Coelho. São Paulo: Tipografia Alemã, 1874, p. 234. 
Todas as ideias brotam dela - "como da árvore brota a flor" ${ }^{20}$-, e, na mente daqueles que permitem sua livre expressão, a imaginação pode criar "castelos encantados". ${ }^{21}$ Porém, a imaginação interpõe-se entre o real e as percepções que suscita e, por essa razão, aquele que se deixa levar por ela, particularmente o poeta, será "o mais feliz, e ao mesmo tempo o mais desgraçado dos homens; porque, na fruição de prazeres, e no sofrimento dos desgostos, o poeta goza mais do que há, e sofre o dobro do que em realidade existe". ${ }^{22}$ Já responsável por alterar a percepção do real de qualquer ser humano, e ainda mais daquele tocado pela poesia, a imaginação e suas "garras de fogo" intensificam-se e autonomizam-se se mescladas com os coloridos e com os temores da paixão. ${ }^{23}$ Louva-se a faculdade imaginativa pelo impulso com que dota a consciência do poeta, transportando-a da mera realidade a um espaço em que se pudesse expandir pela liberdade de criação. ${ }^{24}$ Ainda, como uma faculdade inerente à constituição humana, dialoga com a natureza, dependendo por vezes de suas variações para atuar: "Este frio enregela-me as asas da imaginação; este vento glacial, que uiva pelos telhados, como uma matilha de cães danados, estes guinchos de corujas, que parecem lamentos de precitos, fazem a inspiração recolher-se toda encolhida aos mais íntimos esconderijos do crânio, tiritando de frio e de medo".25

Alguns homens podem ter a capacidade de apreender objetos da realidade empírica e de representá-los mentalmente de maneira viva, sem, contudo, dominarem o instrumental necessário para bem materializá-los de forma artística, por mais que "a viveza da sua imaginação" povoe cada um de seus pensamentos. Há uma grande diferença entre o projeto de uma obra e a sua execução final, “a distância que vai do ar a um sólido, do espírito à matéria”, entre o mundo das ideias e o da representação objetiva, entre o sutil e o vigente: “a imaginação tem cores que se não desenham”. Sua plasmação possui “sempre um quê de material”: há um crivo entre o caráter abstrato

20 Idem. Alfarrábios: Crônicas dos tempos coloniais. Vol. 1. In: O Garatuja. Rio de Janeiro: Garnier, 1873, p. 69.

21 Idem, Sonhos d'ouro. Tomo 2. Rio de Janeiro: Garnier, 1872, p. 236.

22 MaCedo, Joaquim Manuel de. Os dois amores. Tomo 2. Rio de Janeiro; Paris: Garnier, 1887, p. 152.

23 Idem, Rosa. Tomo 2. Rio de Janeiro; Paris: Garnier, s.d., p. 174.

24 AzEvedo, Álvares de. “O poema do frade” (Biblioteca Universal Antiga e Moderna) Lisboa: Companhia Nacional Editora, 189o, p. 18 (Acervo da Brasiliana, Biblioteca Digital da Usp, Universidade de São Paulo). 25 guimarães, Bernardo. “A cabeça do Tiradentes”. In: HigA, Mário (org.) Antologia de contos românticos. São Paulo: Lazuli Editora; Companhia Editora Nacional, 2012, p. 215. 
da imaginação e a concretude da obra de arte, que diz respeito também às ideias que são representadas nela. ${ }^{26}$

O grau de autonomia da faculdade imaginativa é relativizado, pois ela tanto pode seguir suas próprias normas de conduta, quanto servir apenas de impulso para a formulação de imagens mentais. As ideias e os fatos estão no mundo e, por vezes, passam indiferentemente diante dos olhos dos seres humanos. Embora, em aparência, "vulgares", tais objetos não escapam da apreensão autônoma da reflexão, que "trabalha sem descanso" sobre eles, a ponto de transmudá-los em uma forma mais "brilhante" e "bela". Após a reflexão da inteligência sobre a matéria literária, a imaginação se encarrega de, partindo das características inerentes a cada material, verificar quais delas se distinguem como traços únicos, como tendências principais, quaisquer que sejam, para sobre elas apoiar a concepção da forma artística. ${ }^{27}$

"A imaginação se lança no espaço, percorre mundos desconhecidos, atravessa o tempo e a distância, e vai muitas vezes acordar os ecos do passado, revolver as cinzas das gerações extintas, ou contemplar as ruínas de uma cidade opulenta, de um vasto império abatido." ${ }^{28}$ Aos escritores se reservam "direitos confessos de imaginação" que são, no entanto, relativizados pela factibilidade dos acontecimentos narrados: é condenável "falsificar a história, dando por fatos averiguados alguns devaneios de imaginação". ${ }^{29} \mathrm{~A}$ imaginação se espraia pelas lacunas que essa disciplina deixa, inventando livremente, porém, apenas nos pormenores perdidos dos grandes acontecimentos; por fim, mais os revigorando do que criando.

No fundo dessa subordinação da imaginação à história está a crítica a todo o seu exercício excessivo - ademais, "os mais arrojados esforços da imaginação" podem esgotar a fonte de onde ela se origina. ${ }^{30}$ Há consequências extremas e perigos efetivos para a moral e para a vida em sociedade originados no exercício autônomo da imaginação,

\footnotetext{
26 DIAs, Gonçalves. “Prólogo a Leonor de Mendonça”. In: FARIA, João Roberto. Ideias teatrais: o século XIX no Brasil. São Paulo: Perspectiva, 2001 [1846], p. 346.

27 DIAs, Gonçalves, op. cit., p. 345.

28 AlenCAR, José de. Alfarrábios: Crônicas dos tempos coloniais. Vol. 1. In: O Garatuja. Rio de Janeiro: Garnier, 1873, p. 147 .

29 MACEDo, Joaquim Manuel de. Memórias da rua do Ouvidor. Rio de Janeiro: Tipografia Perseverança, 1878 , pp. 11 e 120.

30 TAUnay, Silvio Dinarte Escragnolle. Estudos críticos. Vol. II. In: Literatura e philologia. Rio de Janeiro: Leuzinger \& Filhos, 1883 , pp. 51-2 e 53.
} 
pela possibilidade de esta conceber um mundo à parte, de horizontes indefinidos e desconhecidos, no interior do qual segue "seus caprichos de menina volúvel", criando e recriando, dialogando tão somente com os objetos e seres por ela mesma elaborados. ${ }^{31}$ Mas os verdadeiros perigos da autonomia extremada da imaginação não se encontram apenas nos enganos da vida cotidiana, amorosa ou social, mesmo os mais dolorosos. A influência da atividade da faculdade imaginativa pode conduzir a distúrbios mentais, "doenças da imaginação", passíveis de receberem tratamento clínico. ${ }^{32}$ Nesse aspecto, a plasmação do sofrimento na literatura é vista como uma solução para evitar os excessos imaginativos: "com a exposição da sua última aventura amorosa, sua sensibilidade e imaginação facilmente inflamáveis o arrojariam menos aos acidentes imprevistos e aos perigos do romanesco e do maravilhoso". ${ }^{33}$

Em resumo, como continuador parcial das doutrinas filosóficas do século XVIII, o termo imaginação refere-se a uma faculdade inerente a qualquer ser humano, não se restringindo ao campo da arte, mas se dilatando para outros domínios: ele elabora todas as ideias que existem no mundo. Seu caráter evocativo, e não apenas mnemônico, personifica ideias e objetos, unificando o presente e o passado em uma representação intensa, embora limitada. Ainda se baseando na realidade empírica, a imaginação retoma sensações e emoções, ligando-as às ideias que estão no mundo e que podem ser captadas pelos órgãos dos sentidos, trabalhando-as artisticamente para que sejam dotadas dos critérios de beleza e equilíbrio, ainda que partindo de características que lhes são inerentes. Mesmo o poeta, o único que possui à mão o instrumental necessário para expressar as ideias que sua imaginação elabora, não consegue externar todas as representações que são fruto dessa faculdade. Seu trabalho não é o de apenas se afastar da realidade empírica (na verdade, deve evitá-lo, se possível, principalmente nos casos em que tal afastamento ferir a moral e os costumes da sociedade, ou negligenciar a construção de um ideário nacional), mas também de exprimir o belo. Na contramão da antítese, que considera a intensidade um dos critérios da poesia, a imaginação passa por um cerceamento parcial, mas deliberado.

31 "Depoimento do crítico Pedro Luís". In: Abreu, Casimiro de. Obras completas de Casimiro J. M. de Abreu, Biblioteca dos Melhores Autores Antigos e Modernos. Rio de Janeiro: Garnier, 1877, p. 16. 32 MACEdo, Joaquim Manuel de. A luneta mágica. Tomo 1. Rio de Janeiro: Garnier, s.d., p. 140. 33 Idem. Os quatro pontos cardeais. A misteriosa (romances). Rio de Janeiro: Garnier, s.d., pp. 183-4. 
No que diz respeito aos riscos que o excesso de imaginação pode proporcionar, seu posicionamento também é particularmente setecentista, já que os aspectos negativos da imaginação mal são mencionados nas poéticas dos românticos europeus: nestes, mesmo sem se negar a capacidade racional, a imaginação é compreendida como faculdade que se interpõe entre a realidade e sua captação pelos sentidos, entre o pensamento e o mundo, excedendo essa base para a percepção sensível, sem com isso ocasionar o sentido patológico da imaginação, e seu terreno se torna o do factível. Nos usos do termo imaginação no Brasil, a expressão da emotividade diante da realidade altera sua percepção, intensificando ou esmorecendo os sentimentos do homem comum ou do poeta. A liberdade imaginativa, situando-se no campo das ideias, é compreendida como um modo de suportar a realidade e o sofrimento. As consequências do exercício da imaginação na sociedade são mais negativas para o romantismo no Brasil, pois, no romantismo europeu, essa faculdade fornece uma perspectiva mais ampla para os acontecimentos, funcionando como uma escola de sensibilização para a sociedade, pelo exercício da ficção. No Brasil, contudo, além da referência à loucura, a expansão imaginativa traz como consequência o abandono das normas morais da sociedade, o que, em uma sociedade em formação, traria mais malefícios que benefícios.

Porém, expandindo-se dos fatores de isolamento social e insanidade que são pauta no enciclopedismo e no sensualismo, a imaginação no Brasil adere aos valores moralistas e conservadores que partem em grande medida dos preceitos da religião cristã, de grande força no romantismo. Da antítese, a imaginação no Brasil toma ainda emprestada sua imprescindibilidade não apenas como essência da obra literária, mas como fonte do instrumental necessário à sua elaboração, e ainda suas possíveis origens naturais ou adquiridas (místicas) ${ }^{34} \mathrm{e}$ sua capacidade de expandir a consciência do poeta e, consequentemente, seu potencial de criação. Como herdeiro de duas concepções que se contrapõem e complementam, o termo imaginação por vezes toma emprestados sentidos de uma ou outra ou os mescla. Porém, é importante observar, a síntese referida entre universalismo e particularismo, entre objetivo e subjetivo, pertence, no romantismo brasileiro, mais às ideias do que às formas literárias que as expressam. Na prática literária, o mesmo conceito ensejou desde obras mais realistas, como as de Gonçalves de Magalhães e José de Alencar, até obras em que a expansão da realidade empírica servia de alicerce, como as de Álvares de Azevedo e Bernardo Guimarães.

34 ALENCAR, José de. Ao correr da pena, cit., pp. 3-4. 


\section{4. “DOCUMENTO É MONUMENTO”}

Questionando a suposta intencionalidade do monumento, como "herança do passado", e a imparcialidade do documento, "escolha do historiador", Jacques Le Goff ${ }^{35}$ observa que o conhecimento que permanece sobre o passado não traduz aquilo que verdadeiramente se passou, mas é fruto de uma seleção consciente tanto dos legítimos enunciadores de um discurso, quanto do cientista que se dispõe a analisá-lo e o faz "falar". Os documentos que conscientemente selecionamos, os quais também são patrimônios da teoria, da crítica e da literatura oitocentista no Brasil e, portanto, legados de um tipo de reflexão e pensamento, são caracterizados pelo categórico elogio da imaginação, como fundamento da criação literária romântica, e por sua negação, como faculdade que deveria ser dosada e subjugada a outras faculdades e disciplinas.

A imaginação está presente, como termo e como conceito, nesses documentos do passado. Consideramos, ainda, que "o documento é monumento. Resulta do esforço das sociedades históricas para impor ao futuro - voluntária ou involuntariamente - determinada imagem de si próprias". ${ }^{6} \mathrm{O}$ questionamento se amplia e não se esgota: afinal, qual imagem de si próprios os escritores oitocentistas almejavam legar ao futuro, já que nem toda afirmação ou negação da imaginação pela crítica e pelos autores românticos representam uma afirmação ou negação significativamente reais para essa faculdade na plasmação virtual das obras?

No Brasil, embora a imaginação seja muitas vezes compreendida como polêmica faculdade ou potência de imitação e memória, em parte submissa a outras instâncias, como a razão, a história e a linha narrativa, e perigosamente situando-se como um excesso e até mesmo como um distúrbio mental, ela não deixa de ser percebida pelos nossos escritores como um importante elemento da concepção de obras artísticas, mesmo naquelas de fortes traços descritivos, dotada de certo grau de autonomia e passível de ser expandida pelo trabalho criativo. Eles a mencionam em seus prefácios, em suas críticas - enfim, a imaginação não deixa de estar presente no romantismo no Brasil, e é afirmada mesmo quando aparentemente não está lá, mesmo quando é disposta de modo esparso e heterogêneo. São definições por vezes contraditórias, mas que convivem

35 LE GOFF, Jacques. História e memória. Tradução de Bernardo Leitão. Campinas: Editora da Unicamp, 1990, p. 548. 36 Ibidem. 
necessariamente, como parte de um romantismo que não se estabeleceu como ruptura com os moldes neoclássicos fortemente arraigados na literatura do Brasil. Tais indefinições do conceito de imaginação também derivam da inexistência de uma oposição totalizante e ferrenha entre o classicismo e o romantismo, já que essa antinomia se dá antes na apreensão particularizada de alguns preceitos.

A imaginação é uma faculdade inerente a todos os seres humanos, intensificada na mente artística, responsável pela elaboração de todas as ideias passíveis de serem realizadas pela mente humana, principalmente aquelas ligadas ao campo da arte, nas quais representa elaboração e criação. Sem ocupar a supremacia entre eles, mas fornecendo o espaço expressivo que a cada um pertence por direito, forma, em conjunto com a memória, a razão, os sentidos e a emotividade ou o sentimento, os fundamentos do conhecimento humano sobre a realidade. Mesmo por vezes em contradição com o resultado final obtido em obras literárias mais despregadas da realidade empírica, é uma faculdade em suas bases teóricas imagética, objetiva e de traços realistas, possuindo caráter evocativo, e não apenas mnemônico.

Dentre os principais atributos ligados ao termo estão: a autonomia parcial que possui no processo de elaboração de representações em relação ao ser que imagina e no que diz respeito ao que ele imagina; sua constante ligação, mesmo que em diferentes graus, com os órgãos dos sentidos e com as respectivas sensações que suscitam; o representar, quando em excesso, riscos à saúde mental, precisando por isso ser dosada; o vínculo de suas representações com a emotividade do ser humano, a qual acarreta modificações fundamentais em seu produto final; a impossibilidade que impõe ao ser humano em exteriorizar totalmente as ideias que suscita. O termo imaginação, como sintese de tendências universalistas e particularistas, do subjetivo e do objetivo, representou um dos caminhos para a expressão do imaginário e do simbólico na literatura oitocentista, mas não se confunde com eles. Seu trabalho é de mediação, de representação, de presentificação dessas ideias. A imaginação é, no fim das contas, a tensão que articula o texto e a (ir)realidade que ele exprime.

Jéssica Cristina Jardim é Doutoranda em Literatura Brasileira da Universidade de São Paulo 